\title{
RESEARCH ON THE RELATIONSHIP BETWEEN URBAN AIR POLLUTION AND NOISE LEVELS IN AREAS WITH HEAVY TRAFFIC
}

\author{
Mihai Bratu*, Valeriu Danciulescu, Elena Bucur, Andrei Vasile \\ National Research and Development Institute for Industrial Ecology - ECOIND, 71-73 \\ Drumul Podu Dambovitei Street, sector 6, zip 060652, Bucharest, Romania \\ cmm_bratu@yahoo.com
}

\begin{abstract}
Despite being a less frequently considered type of environmental pollution, noise has a major negative impact on the quality of life in cities. As seen by an extensive survey of environmental noise, the commonest sources of urban noise are known to be transport, industry. Although many different types of pollution may be expected to show correlations, only a number of studies have focused on examining the relationships between street noise and ambient air quality and their combined impacts on the surrounding environment.

Environmental issues are extremely complex and cover all sectors: economic, social and political. Accelerated urbanization of modern cities produced an urban environmental pollution, so that air quality can be affected. The paper presents some preliminary studies regarding the correlation between noise pollution and the concentrations specific pollutants road traffic. The measurements have been conducted at different distances from some very busy roads and crossroads in order to determine a pattern. The data have been processed with a statistical analysis program in order to establish if the noise level can be used to assess the urban air pollution generated by traffic.

Most of the results indicate a good correlation between noises, specific pollutants road traffic. Noise level can be a good indicator for air pollution, especially for the situation when there is no need of a precise determination.
\end{abstract}

Keywords: air pollution, noise, road traffic, specific pollutants

\section{Introduction}

The environment is an essential element of human existence and is the result of multiple interferences of natural elements with artificial elements created by human activity. Ensuring a proper quality of the environment, protecting it as a necessity of survival and progress is a matter of major current interest from the point of view of social evolution.

Environmental protection and pollution reduction are important topics today, both for science and society. Environmental issues are extremely complex and cover all sectors: economic, social and political. Pollution, as it is known, is the contamination with materials harmful to health, quality of life or normal functioning of natural ecosystems.

Bucharest is one of the most crowded and polluted capital from Europe. Economical evolution conducted to a very big rise in number of cars on the streets (almost two millions, including the ones in transit and supply vehicles) [1-3].

Noise, considered a very important part of environmental pollution, has a major negative impact on the quality of life in cities. The most frequent noise 
sources in urban environments are transport and industry. Traffic can have a very big contribution to environmental damage because of the noise and specific chemical products emitted in the environmental air: $\mathrm{NO}_{2}, \mathrm{SO}_{2}$ and $\mathrm{CO}$.

Therefore, a correlation between noise level and chemical pollution caused by heavy traffic can represent a good instrument of environmental quality assessment [4-9].

This paper aims to: (a) identify the existence of a correlation between the noise level and the concentration of $\mathrm{NO}_{2}, \mathrm{SO}_{2}$ and $\mathrm{CO}$ from outdoor air; (b) establish the relationships between these indicators with the purpose to assess the environmental pollution, starting from noise level measurements. Monitoring data have been obtained during a case study conducted in May 11-14, in a crossroads in Bucharest.

\section{Experimental}

Sampling points. A crossroads in Bucharest was chosen for the experimental part, in the south of Bucharest in areas without industrial activities, located nearby to two roads characterized by heavy traffic. In these conditions we can estimate that both noise and chemical pollution are resulted mainly from heavy traffic. Measurements were carried out simultaneously in three distinct located at different distances from road artery. (Fig. 1), therefore:

- Point 1 was located nearby the street (geographical coordinates $\left.44^{\circ} 23^{\prime} 47,87^{\prime \prime} \mathrm{N} 26^{\circ} 06^{\prime} 36,02^{\prime \prime} \mathrm{E}\right)$ so the influence of traffic is as big as possible;

- Point 2 is located behind an eight-storey block (geographical coordinates $44^{\circ} 23^{\prime} 49,16^{\prime \prime} \mathrm{N} 26^{\circ} 0637,64^{\prime \prime} \mathrm{E}$ );

- Point 3 is located straight, perpendicular on the line of the road, at $50 \mathrm{~m}$

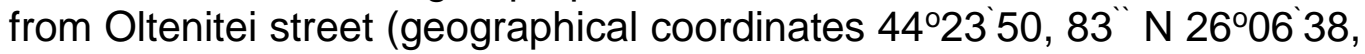
83 "E).

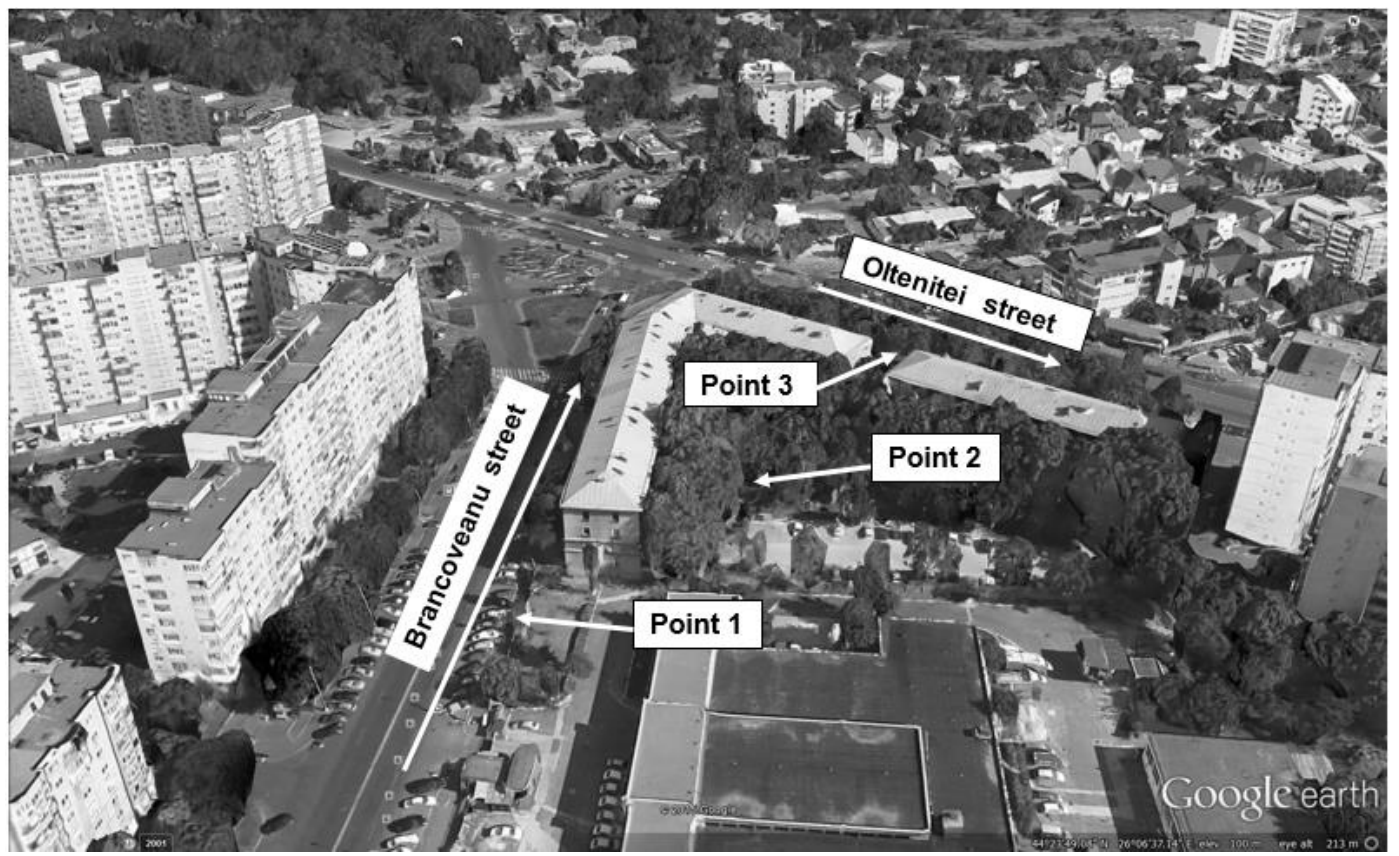

Figure. 1. Crossroads Oltenitei - Brancoveanu and the points: $P 1, P 2$, and $P 3$ 
For the parallel continuous measurements in all three points were used three class 1 noise meters (one SOLO 01 Metravib ,Svantek and Bruel\&kKjaer , each of them provided with octave filter capable to determine the level of acoustical pressure depending on the frequency); the concentrations of chemical pollutants were continuously monitored, using two Graywolf analysers that can measure in parallel all three indicators, installed in points 2 and 3 , one analyser Environment $\mathrm{AF} 22$ for $\mathrm{SO}_{2}$ and one analyser Environment MMS for $\mathrm{CO}$ and $\mathrm{NO}_{2}$, installed in point 1. Air was sampled from $1.5 \mathrm{~m}$ height and the concentrations were recorded in hourly averages. During the tests, the meteorological conditions were favorable for optimal monitoring, with a value of: $21^{\circ} \mathrm{C}$ for temperature, 1014 mbar for pressure, $68 \%$ relative humidity $(\mathrm{RH})$ for humidity and the wind speed was $1.4 \mathrm{~m} / \mathrm{s}$ blowing from north-east (from the source of pollution to the monitoring points).

\section{Results and Discussion}

Results should be clear and concise. Discussion should explore the significance of the results of the work, not repeat them. Avoid extensive citations and discussion of published literature.

\section{LEVEL OF CHEMICAL AND NOISE POLLUTION IN THE AREA}

The monitoring results and the variation in time of $\mathrm{NO}_{2}, \mathrm{SO}_{2}, \mathrm{CO}$ and noise pollution are presented in Fig. 2. (a,b,c,d).
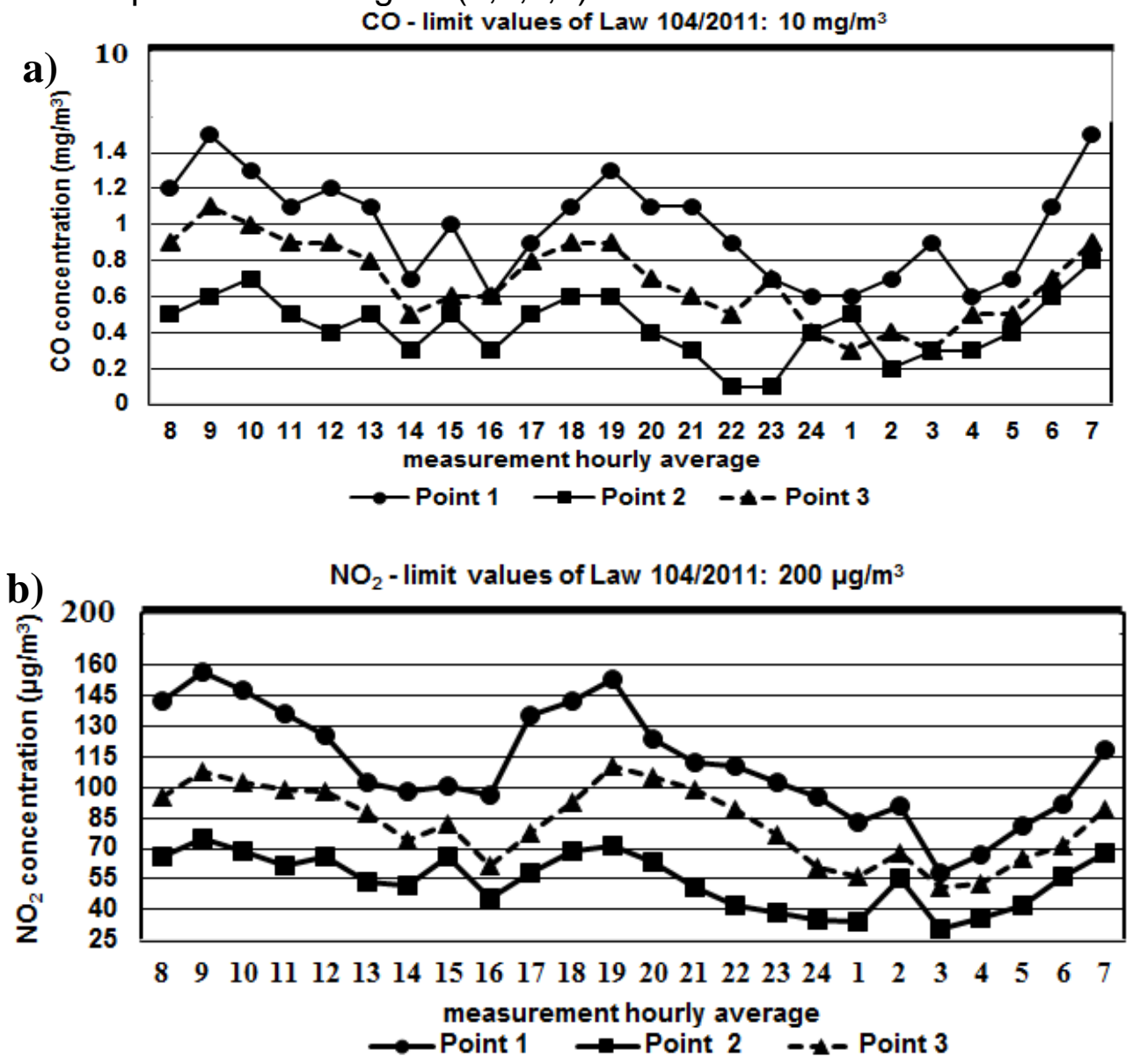

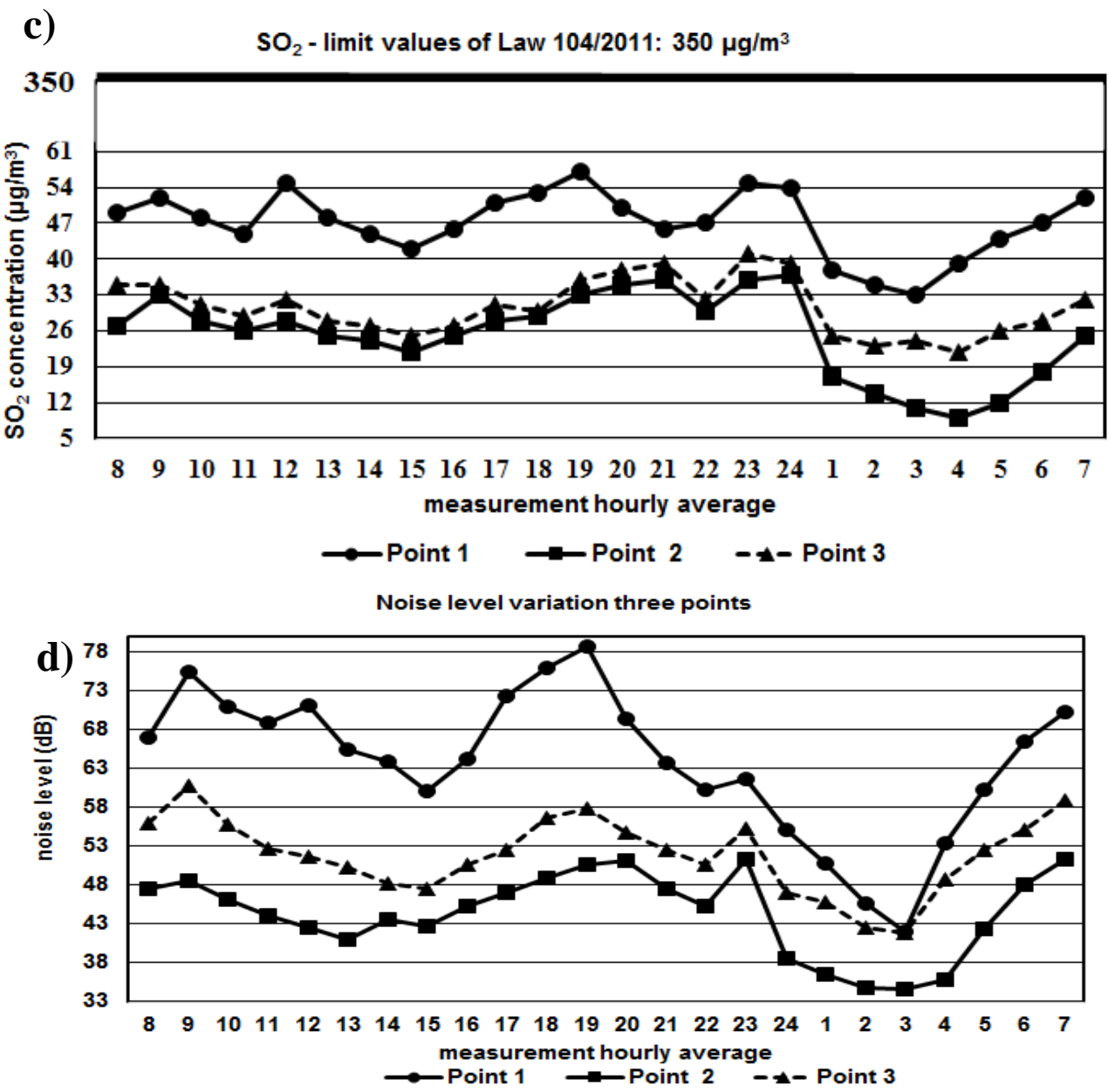

It can be observed that highest concentrations both for chemical pollutants and for noise level are found in point 1, the one located closest to the road. In points 2 and 3 the concentrations are smaller for all concentrations measured, because of the big block of flats located between the road and the monitoring place for point 2 and because of the big distance from the source of pollution for point 3.

By comparison with the values imposed by the environmental legislation, Law 104/2011, it can be observed that the values are under the limits, for both locations [10].

\section{STATISTICAL TREATMENT OF DATA}

In order to identify and establish the correlations between the indicators monitored, the Pearson correlation test has been conducted [. The value of the Pearson correlation test can be used in order to consider how strong the correlation between two sets of data is; thus, for values of the coefficient comprised between $\pm(0.8$ and 1$)$ the correlation is very good, between $\pm(0.6$ and 0.8$)$ the correlation is good, between $(0.4$ and 0.6$)$ the concentration is medium and for values between $\pm(0.2$ and 0.4$)$ and $\pm(0.0$ and 0.2$)$ the correlations are weak or very weak. 
Analyzing the results of correlation analysis for all three points, a very good correlation can be observed between the noise level and chemical pollutants ( $R$ value between 0.7 and 0.95$)$ [13].

\section{Conclusions}

The main conclusions drawn from results should be presented in a short Conclusions section. Do not include citations in this section.

$>$ Noise and chemical air pollution from large urban areas represents a major problem both for the health of the people and for authorities.

$>$ Continuous monitoring of the air quality and noise level, because of particularities of different areas from large cities need important investments for the acquisition and maintenance of automated analyzers necessary to monitor each indicator.

$>$ The results obtained in the tests presented in this paper reveal good and very good correlation between noise level and concentration of $\mathrm{NO}_{2}, \mathrm{SO}_{2}$ and $\mathrm{CO}$ in the air, in a crossroads of Bucharest where the most important common source of pollution is traffic.

$>$ In these circumstances we believe that for urban areas in which the most important source of pollution is traffic (common source of noise and chemical pollution) by monitoring the noise level can be obtained important clues regarding the chemical pollution of air through relationships obtained using linear regression without being necessary to monitor all chemical pollutants.

\section{Acknowledgements}

The tests were done inside the Program Nucleu financed by the Ministry of Education and Research of Romania whom we thank with this opportunity for all the support.

\section{References}

1. ANCA G. ANCA, SIMION C. SIMION, (2007): Environmental Protection, BREN, Bucharest.

2. GRIGORE F., ROJANSCHI V., (2004), Environmental Management Systems A New Concept in Environmental Protection and Rehabilitation. Scientific Bulletin of the Faculty of Ecology (Earth, Pitesti), (3), 143 .

3. S. P. KARAKITSIOS, C. L. PAPALOUKAS, P. A. KASSOMENOS, G. PILIDIS: Assessment and Prediction of Benzene Concentrations in a Street Canyon Using Artificial Neural Networks and Deterministic Models: Their Response to "What If' Scenarios. Ecol Model (2006), 193, 253 
4. K. H. KIM, D. X. HO, R. J. C. BROWN, C. G. PARK, I. C. RYU: Some Insights into the Relationship between Urban Air Pollution and Noise Levels. Sci Total Environ, 424, 271, 2012.

5. J. M. FIELDS: An Updated Catalog of 521 Social Surveys of Residents' Reactions to Environmental Noise (1943-2000). NASA/CR-2001-211257, 2011.

6. A. CAN, M. RADEMAKER, T. V. RENTERGHEM, V. MISHRA, M. V. POPPEL, A. TOUHAFI: Correlation Analysis of Noise and Ultrafine Particle Counts in a Street Canyon. Sci Total Environ, 409 (3), 564 (2011).

7. R. W. ALLEN: Are Both Air Pollution and Noise Driving Adverse Cardiovascular Health Effects from Motor Vehicles? Environ Res, 111 (1), (2011).

8. N. ELIOU, K. VOGIATZIS, F. KEHAGIA: Evaluation of Noise Levels in Urban Environment in Greece. WSEAS-Int J Sustain Dev Plan, 82, 1065 (2006).

9. B. BARITI, I. MALOLLARI, N. LAJCI, M. SADIKU, S. NIKSHIQ-KADRIU, M. ALIU, B. SYLA, P. HOXHA: Assessment of Noise Pollution Risk at Hotels in Mitrovica - Kosovo. J Environ Prot Ecol, 15 (4), 1519 (2014).

10. Law 104/2011 on Ambient Air Quality.

11. R. Månsson, P. Tsapogas, M. Åkerlund, A. Lagergren, R. Gisler, M. Sigvardsson: Pearson correlation analysis of microarray data allows for the identification of genetic targets for early b-cell factor. J. Bio. Chem, 279(17), 17905(2004).

12. S. Bayram, S. Gultekin, S. Gezici: noise enhanced hypothesis-testing according to restricted Neyman-Pearson criterion. Digital Signal Processing (DSP), 25, 17(2014).

13. W.STEFANESCU, P.STEFANESCU: Aspects regarding the level of acoustic discomfort generated by urban traffic. J Environ Prot Ecol, 13 (4), 2087 (2012). 